\title{
Increased Expression of Extracellular Glutathione Peroxidase in Mice with Dextran Sodium Sulfate-Induced Experimental Colitis
}

\author{
DORIS M. THAM, JOHN C. WHITIN, AND HARVEY J. COHEN \\ Department of Pediatrics, Stanford University School of Medicine, Stanford, California 94305, U.S.A. \\ [D.M.T., J.C.W., H.J.C.]
}

\begin{abstract}
Extracellular glutathione peroxidase (E-GPx) is a selenoenzyme that reduces hydrogen peroxide and organic peroxides. All plasma glutathione peroxidase (GPx) activity in humans is attributable to E-GPx. The gastrointestinal (GI) tract also synthesizes and secretes E-GPx into the extracellular milieu. Endogenously generated oxidants have been implicated in inflammatory bowel disease (IBD). We evaluated E-GPx levels in a mouse model of IBD using dextran sodium sulfate (DSS). Histologic lesions of the lower GI tract consisted of multifocal areas of mucosal erosion denuded of epithelial cells, reduction in goblet cells, dilated crypts, crypt collapse, submucosal edema, and transmural distribution of mixed inflammatory infiltrates. On d 7, plasma GPx activity in the DSS group increased by $61 \%$ compared with the control group $(p<0.05)$. Western blot analysis demonstrated a $64 \%$ increase in E-GPx protein in the plasma of the DSS group after $7 \mathrm{~d}$ of treatment $(p<0.01)$. As the major source of plasma GPx is the kidney, we determined whether the increase in plasma GPx activity and protein was caused by a change in E-GPx synthesis by the kidney. After 3 and $7 \mathrm{~d}$ of DSS treatment, E-GPx mRNA levels, relative to
\end{abstract}

\section{ABSTRACT}

glyceraldehyde-3-phosphate dehydrogenase, increased in the kidney $(p<0.05)$ without a concomitant increase in cellular GPx mRNA on $\mathrm{d} 7$. These results suggest that the inflammatory injury in the intestine elicits an increase in E-GPx in the plasma that is associated with an increase in E-GPx mRNA in the kidney. This implies that renal production of E-GPx may be sensitive to insults distal to the kidney. (Pediatr Res 51: 641-646, 2002)

$\quad$ Abbreviations
E-GPx, extracellular glutathione peroxidase
C-GPx, cellular glutathione peroxidase
GPx-GI, gastrointestinal glutathione peroxidase
GPx, selenium-dependent glutathione peroxidase
IBD, inflammatory bowel disease
DSS, dextran sodium sulfate
GI, gastrointestinal
t-BuOOH, tert-butyl hydroperoxide
GSH, glutathione
SSC, saline-sodium citrate
GAPD, glyceraldehyde-3 phosphate dehydrogenase

IBD, such as Crohn disease and ulcerative colitis, cause chronic injury to the GI tract. Considerable debate still exists as to whether oxygen-derived species are involved in the pathogenesis of tissue injury or are endogenously generated as a consequence of damaged tissue. Free radicals have been implicated in the genesis of colonic diseases, such as ulcerative colitis $(1,2)$, and in vitro studies using enterocytes have demonstrated the damaging effects of exposure to oxidants (3). Studies have reported that the colons of IBD patients produce more oxygen free radicals compared with those of control subjects (4). In addition, compared with normal mucosa, significantly elevated levels of reactive oxygen metabolites are found in actively inflamed mucosa of IBD patients (5).

Received April 23, 2001; accepted December 17, 2001.

Correspondence and reprint requests: John C. Whitin, Ph.D., Department of Pediatrics, Stanford University School of Medicine, 300 Pasteur Drive, Room S-308, Stanford, CA 94305-5208, U.S.A.; john.whitin@stanford.edu

Supported by NIH grant 2R01-DK 33231.
E-GPx is a selenoenzyme that reduces hydrogen peroxide, organic hydroperoxides, FFA hydroperoxides, and phosphatidylcholine hydroperoxides (6-8). All plasma GPx activity in humans is attributable to E-GPx (9). Relative to other tissues, kidneys have the highest levels of E-GPx mRNA in humans and mice (10-13). Plasma GPx activity in anephric humans ranges from 2 to $23 \%$ of control, which suggests that the kidney is the major source, but is not the sole source of plasma E-GPx (14).

The GI tract contains mRNA for three GPx: C-GPx, E-GPx, and GPX-GI (15). Previous studies have also indicated that the GI tract synthesizes and secretes E-GPx into the extracellular milieu (16). Many studies have demonstrated that antioxidant defenses, such as GPx, are altered in inflammatory diseases involving the GI tract (17). It has been reported that pediatric patients with IBD have increased plasma $\operatorname{GPx}$ activity $(18,19)$. However, the source and identity of this elevated GPx activity has not been investigated. 
We used a model of IBD in young mice to study E-GPx during inflammation of the GI tract. Administration of DSS to mice, in the drinking water, results in acute or subacute colonic inflammation, depending on the protocol. In this model, the colonic inflammation exhibits ulceration, which is reversible. This model is therefore valuable for the study of mechanisms that could act in the pathogenesis of human ulcerative colitis (20). We show that in this model of induced IBD, plasma E-GPx is increased. We show that neither E-GPx mRNA nor protein is increased in the GI tract. Increased plasma E-GPx protein is associated with an increase in E-GPx mRNA levels in the kidney.

\section{METHODS}

Animals. Male $\mathrm{C} 3 \mathrm{H} / \mathrm{HeJ}$ mice (aged $5 \mathrm{wk}$ ) were obtained from Jackson Labs (Bar Harbor, ME, U.S.A.) and maintained under standard laboratory conditions. Ethical considerations in the use of animals in research were followed according to the guidelines administered by the Institution Animal Care and Use Committee (IACUC-Federal) and Administrative Panel on Laboratory Animal Care (A-PLAC-Stanford University).

Induction of DSS-induced colitis. Mice were divided into two groups: control and IBD. The IBD group received water supplemented with 5\% DSS (40,000 kD; ICN, Costa Mesa, CA, U.S.A.). Controls received water without supplementation. Weight, water intake, and stool were monitored daily for both control and IBD mice. After no more than $7 \mathrm{~d}$ of treatment, the control and IBD mice were euthanized by exposure to $\mathrm{CO}_{2}$. Each treatment course consisted of five control and five DSS-treated mice. Treatment course was repeated three times with similar results. All presented data are from one course of treatment.

Histology. Immediately after euthanasia, the cecum, proximal colon, distal colon, and kidneys were harvested. Feces were carefully removed from the GI tract lumen. Tissues were fixed in $4 \%$ buffered paraformaldehyde, $\mathrm{pH} 7.0$, embedded in paraffin, and sectioned $(5 \mu \mathrm{m})$ onto gelatin-coated glass slides. After deparaffinization with xylenes and rehydration through graded ethanol washes $(100 \%, 95 \%, 70 \%, 50 \%$, and $30 \%)$, sections were stained with hematoxylin and eosin.

Isolation of plasma. Immediately after euthanasia, $1 \mathrm{~mL}$ of blood was removed from the right ventricle of the heart into a syringe containing heparin and placed on ice. Plasma was separated from the cellular components by centrifugation at $1000 \times g$ for $10 \mathrm{~min}$ at $4^{\circ} \mathrm{C}$. Samples were kept at $-80^{\circ} \mathrm{C}$ until further analysis.

Plasma GPx activity. GPx activity was measured by an adaptation $(9,21)$ of the method of Beutler $(22)$, using t$\mathrm{BuOOH}$ and GSH as substrates. Activity was assayed in a coupled enzymatic reaction after the oxidation of NADPH at $340 \mathrm{~nm}$, at $37^{\circ} \mathrm{C}$, in a double-beam spectrophotometer (Cary 1E, Varian, Palo Alto, CA, U.S.A.) in the presence of glutathione reductase. The standard reaction mixture contained 0.1 M Tris- $\mathrm{HCl}, \mathrm{pH}$ 8.0, 0.2 mM NADPH, 0.5 mM EDTA, 2 mM GSH, 1 unit of glutathione reductase, and plasma in a total volume of $0.99 \mathrm{~mL}$. The reaction was started by the addition of $10 \mu \mathrm{L}$ of $\mathrm{t}-\mathrm{BuOOH}$ to the sample cuvette only (final concen- tration, $70 \mu \mathrm{M})$. One unit of GPx activity is defined as the amount of enzyme that oxidizes $1 \mu \mathrm{mol}$ NADPH/min. Protein concentration was determined using a modified Lowry assay kit (Bio-Rad, Hercules, CA, U.S.A.), using bovine IgG as the standard.

Western blot analysis. For analysis of expression of E-GPx protein, $100 \mathrm{mg}$ of mouse kidney, cecum, proximal colon, and distal colon were collected, rinsed in PBS, and placed in $1 \mathrm{~mL}$ of protein lysis buffer containing $10 \mathrm{mM}$ Tris, $150 \mathrm{mM} \mathrm{NaCl}$, $0.5 \%$ Triton X-100, $1 \%$ Nonidet P- $40,10 \mathrm{mM} \mathrm{NaN}_{3}, 0.5$ $\mu \mathrm{g} / \mathrm{mL}$ leupeptin, $0.5 \mathrm{mg} / \mathrm{mL}$ pefabloc (Calbiochem, La Jolla, CA, U.S.A.), $0.7 \mu \mathrm{g} / \mathrm{mL}$ pepstatin, $50 \mu \mathrm{g} / \mathrm{mL}$ trypsin inhibitor, and $1.0 \mu \mathrm{g} / \mathrm{mL}$ aprotinin, $\mathrm{pH}$ 7.5. Tissues were homogenized on ice using a Tissue Tearor (Biospecs Products, Inc, Racine, WI, U.S.A.). Protein concentration was determined by the same method as above, and 50 $\mu \mathrm{g}$ of tissue extract or $0.1-50$ $\mu \mathrm{g}$ of plasma was electrophoresed on either $12.5 \%$ (for E-GPx or C-GPx analysis) or $10 \%$ (for albumin analysis) SDSpolyacrylamide gels under reducing conditions (100 mM DTT) and transferred onto a membrane (Hybond-PVDF, Amersham Pharmacia Biotech, Piscataway, NJ, U.S.A.) using a semi-dry electroblotter (Owl Scientific, Woburn, MA, U.S.A.). The membranes were blocked with PBS containing 6\% (wt/vol) nonfat dry milk at room temperature for $1 \mathrm{~h}$ and then incubated for $1 \mathrm{~h}$ with the primary antibody. The primary antibodies were 1) an affinity-purified polyclonal antibody against a peptide specific for mouse E-GPx, 2) an affinity-purified polyclonal antibody against a peptide specific for mouse C-GPx, or 3) an affinity-purified polyclonal anti-mouse antibody against mouse albumin (Accurate Chemical, Westbury, NY, U.S.A.). After washing the membranes in PBS containing $0.1 \%$ polyethylenesorbitan monolaurate (Tween 20), the immunoblots were incubated with the secondary antibody, goat anti-rabbit IgGhorseradish peroxidase, at a 1:20,000 dilution (Pierce, Rockford, IL, U.S.A.) for $1 \mathrm{~h}$ at room temperature. The blots were then developed with Super Signal Pico Western blotting substrate (Pierce). Blots were exposed to x-ray film and were quantified using a Bio-Rad GS-710 Calibrated Imaging Densitometer (Bio-Rad). All blots of tissue also contained a lane of mouse plasma for quantitative comparisons.

Isolation and hybridization of total RNA. One hundred milligrams of kidney, cecum, proximal colon, and distal colon was dissected from the mice and immediately placed in a tissue storage and RNA stabilization solution until further processing (RNAlater, Ambion, Austin, TX, U.S.A.). Total RNA was isolated using an RNA isolation reagent (RNAwiz, Ambion). Ten micrograms of total RNA was electrophoresed in $1.5 \%$ agarose-formaldehyde gels and transferred by capillary action to positively charged Nylon membranes (Nytran Plus, Schleicher \& Schuell, Keene, NH, U.S.A.) using $20 \times$ SSC. Murine E-GPx cDNA (clone 47-A1, from Dr. R. Maser, University of Kansas) was labeled with $\left[\alpha-{ }^{32} \mathrm{P}\right]$ dCTP (specific activity, 3000 $\mathrm{Ci} / \mathrm{mmol}$; PerkinElmer Life Science Products, Boston, MA, U.S.A.) to specific activities $>1 \times 10^{9} \mathrm{cpm} / \mu \mathrm{g}$ using a random-primed polymerase kit (RadPrime Labeling Kit, Life Technologies, Gaithersburg, MD, U.S.A.). The blots were prehybridized and hybridized in $5 \times$ Denhardt's solution, $50 \%$ deionized formamide, $10 \%$ dextran sulfate, $250 \mu \mathrm{g} / \mathrm{mL}$ salmon 
sperm DNA, $1 \%$ SDS, and $2 \times \mathrm{SSC}$ at $42^{\circ} \mathrm{C}$ overnight. The blots were then washed at $55^{\circ} \mathrm{C}$ with the most stringent washing in $0.1 \times \mathrm{SSC} / 1 \% \mathrm{SDS}$ before exposure to a phosphor imaging screen. The screens were scanned and quantified using a BioRad GS-505 Molecular Imager and Multianalyst Software (Bio-Rad). The blots were stripped in boiling $0.1 \%$ SDS for 1 min and checked for background before the next probe was used. The blots were then sequentially probed with murine C-GPx (from Dr. N. Imura, Kitasato University, Japan) and GAPD prepared in identical fashion.

Statistical analysis. Values are expressed as the mean \pm SEM. Statistical analyses comparing control and IBD mice included using two-tailed $t$ test for unpaired values, one-way ANOVA (with a Bonferroni post hoc test) for normally distributed populations, and Kruskal-Wallis ANOVA (with a Dunn post hoc test) for nonnormally distributed populations when comparing groups of three or more using a commercial software program (Prism, Graph Pad, San Diego, CA, U.S.A.). A $p<0.05$ was considered statistically significant.

\section{RESULTS}

Clinical and histologic findings. After $3 \mathrm{~d}$ of administration of DSS as a 5\% solution in drinking water, animals in the IBD group developed loose, bloody stool and rectal bleeding. By d 7 , the weight of the IBD group was only $63 \%$ of control (IBD, $13.0 \pm 0.58 \mathrm{~g}$ versus control, $20.7 \pm 0.67 \mathrm{~g} ; p<0.01$; Fig. 1). This difference was related to both decrease in weight of the IBD group and increase in weight of the control group.

At autopsy, examination of the cecum, proximal colon, and distal colon of the IBD group revealed grossly bloody feces. Hemorrhagic areas were recognizable in the intestinal wall, and there was shortening of the colon.

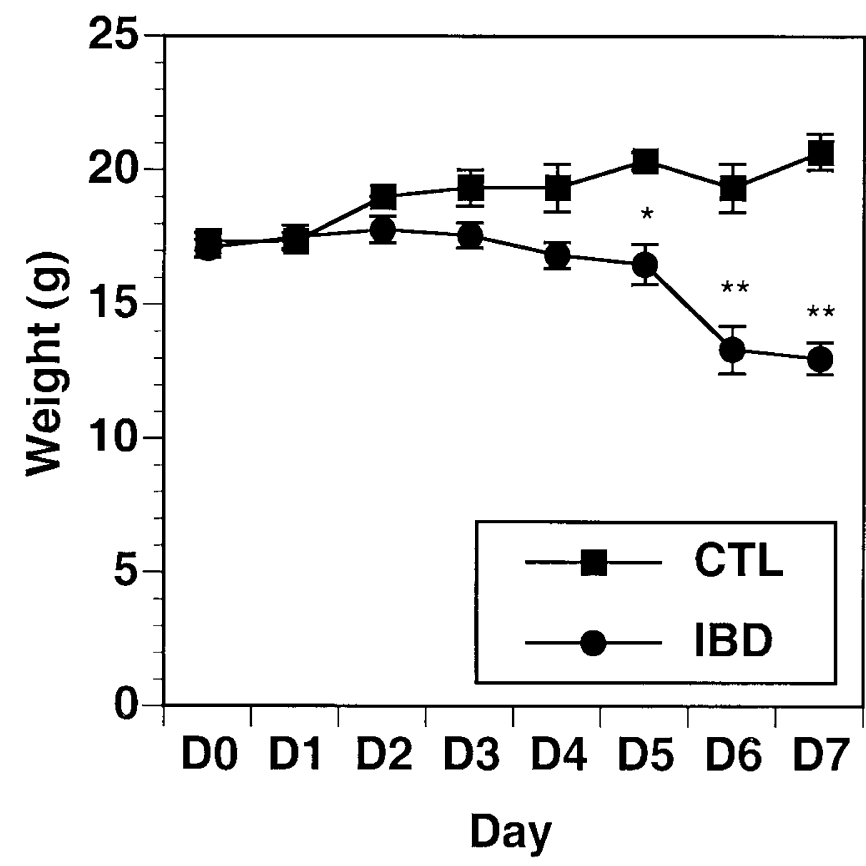

Figure 1. Effects of DSS on mouse weight. By d 7, the weight (in grams) of the IBD group had decreased to $63 \%$ of control (CTL). Statistical analysis was used to compare weight changes between groups $(* p<0.05 ; * * p<0.01$, one-way ANOVA with Bonferroni post hoc test).
The hematoxylin and eosin-stained histologic sections from the IBD group on $\mathrm{d} 7$ revealed lesions of the cecum, proximal colon, and distal colon consisting of multifocal areas of mucosal erosion. The intestinal sections displayed a loss of epithelial cells, reduction in goblet cells, shortening of crypts, dilation of crypts, collapse of crypts, submucosal edema, and transmural distribution of mixed inflammatory infiltrates consisting of macrophages, lymphocytes, and neutrophils (Fig. 2). None of the animals from the control group developed any clinical or histologic signs of colitis.

Plasma GPx activity is increased in mice with IBD. Plasma GPx activity in the IBD group was increased by $61 \%$ compared with the control group after $7 \mathrm{~d}$ of DSS treatment (IBD, $1.72 \pm$ $0.20 \mathrm{U} / \mathrm{mL}$ versus control, $1.07 \pm 0.097 \mathrm{U} / \mathrm{mL}, p<0.05$; Fig. $3 A$ ). Plasma GPx activity normalized per milligram of plasma protein was increased to a similar extent $(64 \%)$ in the IBD group after $7 \mathrm{~d}$ of treatment with DSS (IBD, $0.0463 \pm 0.0030$ $\mathrm{U} / \mathrm{mg}$ versus control, $0.0283 \pm 0.0022 \mathrm{U} / \mathrm{mg} ; p<0.01)$. The plasma protein concentrations for the IBD and control group (IBD, $37.97 \pm 2.56 \mathrm{mg} / \mathrm{mL}$ versus control, $36.89 \pm 3.39$ $\mathrm{mg} / \mathrm{mL} ; p=0.81)$ were not different, indicating the plasma
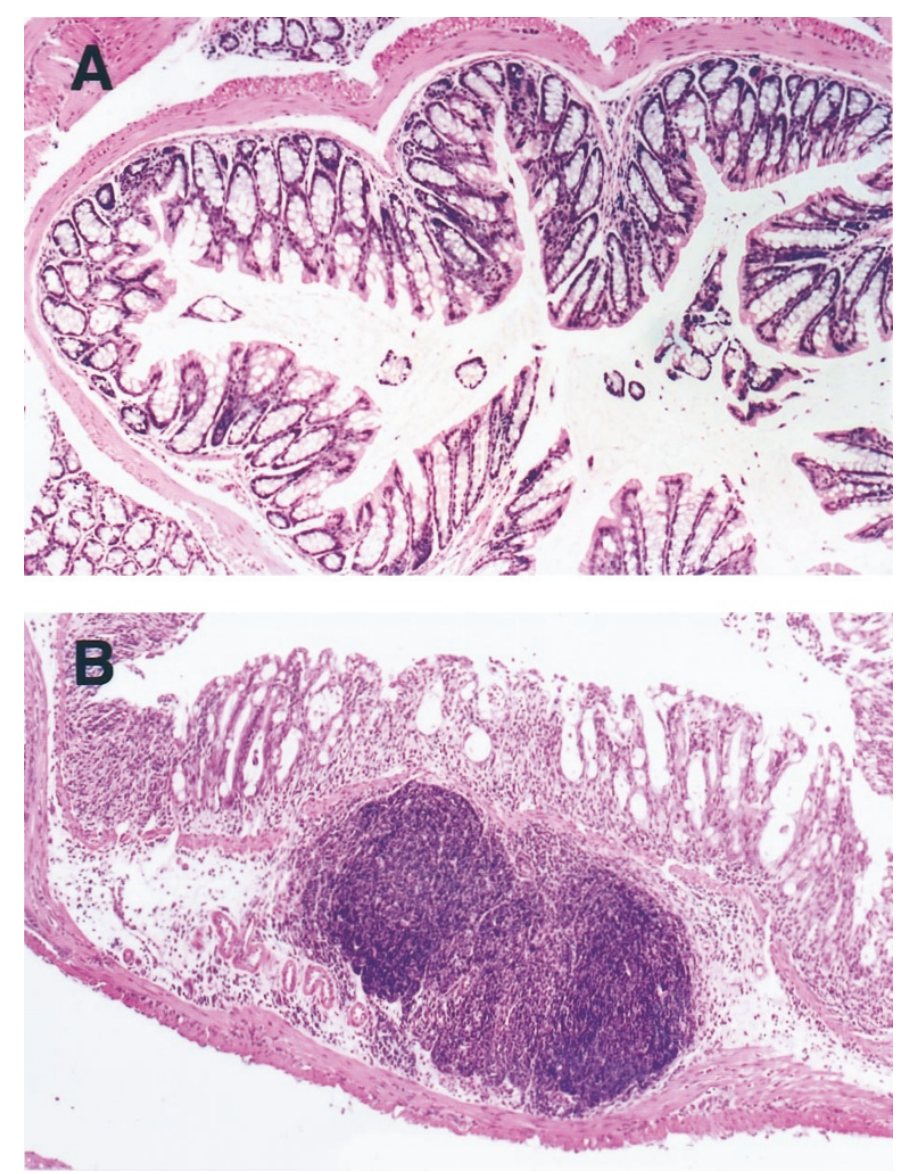

Figure 2. Effects of DSS on mouse proximal colon. Mouse proximal colon sections from both control (CTL; $A$ ) and IBD $(B)$ groups, after $7 \mathrm{~d}$ of DSS treatment, were stained with hematoxylin and eosin. The IBD proximal colon $(B)$ reveals lesions consisting of multifocal areas of mucosal erosion. The intestinal sections displayed a loss of epithelial cells, reduction in goblet cells, shortening of crypts, dilation of crypts, collapse of crypts, submucosal edema, and transmural distribution of mixed inflammatory infiltrates consisting of macrophages, lymphocytes, and neutrophils (magnification, $\times 10$ ). 
volume of the mice did not change. Therefore the increase in plasma GPx activity was not caused by a change in plasma volume.

E-GPX protein is increased in plasma of IBD mice. Western blot analysis of the plasma from the two groups was performed to determine whether the increase in plasma GPx was caused by an increase in E-GPx protein and to determine the source of the increase in plasma E-GPx in this model of IBD. E-GPx protein in the plasma of IBD mice was increased by $64 \pm 11 \%$ after $7 \mathrm{~d}$ of DSS treatment when compared with the plasma of control mice ( $p<0.01$; Fig. $3, B$ and $C$ ). Because equal amounts of protein were loaded in all lanes, the similar increases in activity and protein means that all the increase in plasma GPx activity can be attributed to a specific increase in plasma E-GPx protein. E-GPx protein did not significantly increase in the cecum or proximal colon in mice with IBD (Table 1).

A

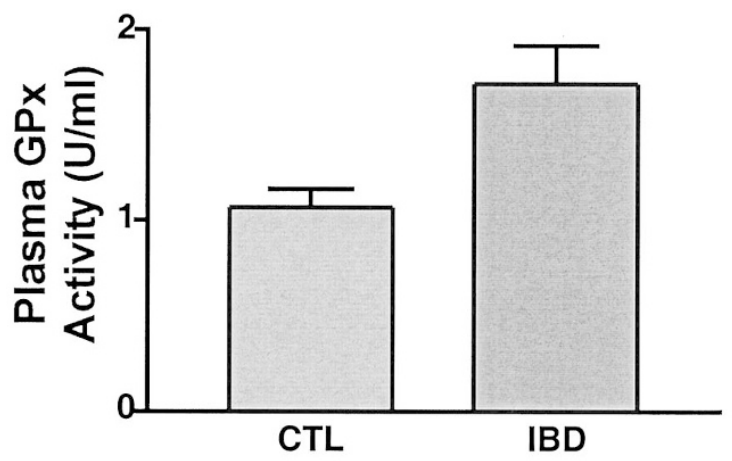

$\begin{array}{llllllll}1 & 2 & 3 & 4 & 5 & 6 & 7 & 8\end{array}$

B

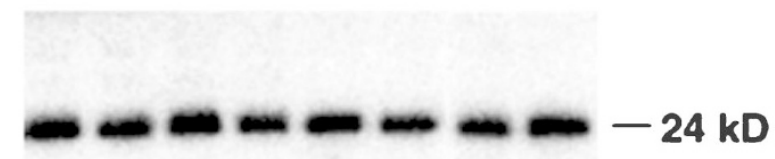

C

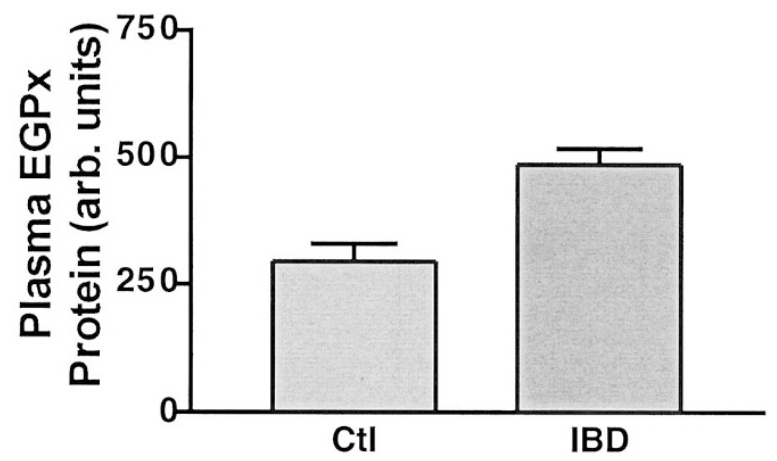

Figure 3. Effects of DSS on mouse plasma GPx activity and plasma E-GPx protein. Plasma activity was measured as described in "Methods." $A$, results for both the control (CTL) and IBD groups after $7 \mathrm{~d}$ of DSS treatment in $\mathrm{U} / \mathrm{mL}$ ( ${ }^{*} p$ $<0.05$, unpaired $t$ test). Plasma E-GPx protein levels were quantified by Western blots as described in "Methods." On d 7, the amount of plasma E-GPx protein $(24 \mathrm{kD})$ in the IBD group $(B$, lanes $5-8)$ is significantly increased compared with CTL ( $B$, lanes $1-4 ; * p<0.01$, unpaired $t$ test). The data are presented as arbitrary densitometry units $(C)$.
Table 1. E-GPx protein in mouse IBD

\begin{tabular}{llcc}
\hline \multicolumn{1}{c}{ Sample } & \multicolumn{1}{c}{ CTL } & IBD (3 d) & IBD (7 d) \\
\hline Kidney & $100 \pm 13.7 \%$ & $148.7 \pm 11.4 \%$ & $116.4 \pm 17.8 \%$ \\
Cecum & $100 \pm 5.6 \%$ & $98.2 \pm 11.9 \%$ & $75.7 \pm 13.4 \%$ \\
Proximal colon & $100 \pm 12.9 \%$ & $90.0 \pm 3.2 \%$ & $86.8 \pm 14.3 \%$ \\
Distal colon & $100 \pm 5.3 \%$ & $96.1 \pm 5.8 \%$ & $66.2 \pm 3.3 \%$ \\
\hline
\end{tabular}

E-GPx protein levels were quantified by Western blots as described in "Methods." Data are presented as percent of control of the mean \pm SEM. The amount of E-GPx protein in the kidney or lower GI tract (cecum, proximal colon, distal colon) in the IBD group is not significantly different from control (CTL) after 3 or $7 \mathrm{~d}$ of DSS treatment.

The amount of albumin in the GI tract also appeared to increase in mice with IBD (Fig. 4), normalized to the protein content of the tissue lysate. This increase in albumin protein in the GI tract of the IBD group may be associated with the hemorrhagic lesions observed during DSS treatment. The amount of albumin in the plasma can then be used to calculate the amount of blood in the tissue lysate. From these measurements and calculations, the distal colon contains $7.0 \pm 0.9 \mu \mathrm{L}$ plasma per milligram of protein in the tissue lysate. Most of the E-GPx in control mouse distal colon is because of the amount of blood in the distal colon ( $\geq 90 \%)$. The amount of blood in the distal colon increased by $352 \pm 133 \%$ in mice with IBD. The calculation for this increase was based on the amount of albumin in the colon of mice with IBD, and was corrected for the actual albumin concentration in the plasma for each mouse (the amount of albumin in plasma decreased by $50 \%$ in mice with IBD). In Table 1, the amount of E-GPx protein in the distal colon was not significantly increased at either $\mathrm{d} 3$ or $\mathrm{d} 7$. However, in one trial, the amount of E-GPx protein in the distal colon increased by $837 \pm 445 \%$ in mice with IBD. Again, this

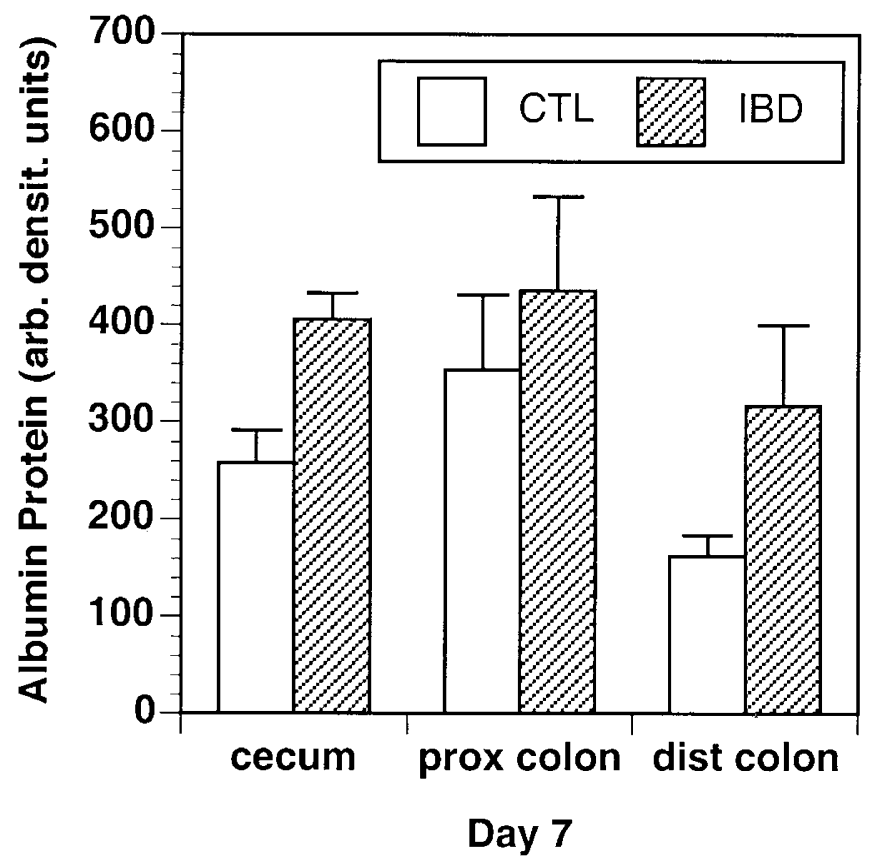

Figure 4. Albumin protein in mouse IBD. Albumin protein levels were quantified by Western blots as described in "Methods." Data are presented as arbitrary densitometry units. On $d$, the amount of albumin protein in the cecum, proximal colon (prox colon), and distal colon (dist colon) of the IBD group is increased compared with control (CTL). 
increase was not statistically different from control, possibly because of the very large variation in the amount of hemorrhage in these sections of distal colon sampled.

The amount of E-GPx protein in the kidney appeared to increase at early points in the development of mouse IBD (Table 1; $3 \mathrm{~d}$ of DSS treatment), although the increase was not significant. The amount of E-GPx protein in the kidney at $7 \mathrm{~d}$ of DSS treatment was not statistically different (Table 1).

The amount of another antioxidant selenoenzyme protein (C-GPx) was also measured in the GI tract of mice with IBD. The amount of C-GPx protein in the lower GI tract did not change in mice with IBD (Table 2). In addition, the amount of C-GPx protein in the kidney of mice with IBD did not change, even after $7 \mathrm{~d}$ of DSS treatment (Table 2).

E-GPX mRNA is increased in the kidney of mice with IBD. Northern analysis of the lower GI tract (cecum, proximal colon, distal colon) and kidney was performed to determine whether there was a change in E-GPx mRNA levels that could account for the increase in plasma GPx in this model of IBD. There was no change in the amount of E-GPx mRNA (normalized to GAPD mRNA) in cecum or proximal colon after $7 \mathrm{~d}$ of treatment with DSS (Table 3). Although there was a trend toward a decrease in relative E-GPx mRNA in the distal colon of the IBD group, it was not statistically significant (Table 3). These data were similar whether the amount of E-GPx was normalized to total RNA (the same amount of total RNA was loaded in each lane) or ribosomal RNA (from the amount of $28 \mathrm{~S}$ ribosomal staining with ethidium bromide; data not shown). In a separate experiment, there was no difference in normalized E-GPx mRNA in the lower GI tract at the earlier points ( $\mathrm{d} 3$ and $\mathrm{d} 5$; data not shown). In contrast, there was a significant increase $(24 \%)$ in the amount of E-GPx mRNA in the kidney of the IBD mice, when normalized to the amount of GAPD mRNA, after $7 \mathrm{~d}$ of DSS treatment ( $p<0.05$; Fig. 5). In addition, we observed a significant increase (29\%) in kidney

Table 2. C-GPx protein in mouse IBD

\begin{tabular}{lcr}
\hline \multicolumn{1}{c}{ Sample } & CTL & \multicolumn{1}{c}{ IBD } \\
\hline Kidney & $100 \pm 22.1 \%$ & $94.1 \pm 16.0 \%$ \\
Cecum & $100 \pm 49.6 \%$ & $125.4 \pm 29.2 \%$ \\
Proximal colon & $100 \pm 29.4 \%$ & $105.2 \pm 12.9 \%$ \\
Distal colon & $100 \pm 22.2 \%$ & $144.3 \pm 35.6 \%$
\end{tabular}

C-GPx protein levels were quantified by Western blots as described in "Methods." Data are presented as percent of control. The amount of C-GPx protein in the kidney or lower GI tract (cecum, proximal colon, distal colon) in the IBD group is not significantly different from control (CTL) after $7 \mathrm{~d}$ of DSS treatment.

Table 3. E-GPx mRNA in mouse IBD

\begin{tabular}{lcc}
\hline \multicolumn{1}{c}{ Sample } & CTL & IBD \\
\hline Cecum & $100 \pm 27.5 \%$ & $83.0 \pm 41.9 \%$ \\
Proximal colon & $100 \pm 22.0 \%$ & $109.9 \pm 29.7 \%$ \\
Distal colon & $100 \pm 41.9 \%$ & $21.9 \pm 5.6 \%$ \\
\hline
\end{tabular}

Total RNA from mouse cecum, proximal colon, and distal colon was isolated and probed by Northern blot analysis as described in "Methods." The amount of E-GPx mRNA is normalized to the amount of GAPD. Data are presented as percent of control. The amount of E-GPx mRNA in the lower GI tract from the IBD group is not significantly different from control (CTL) after $7 \mathrm{~d}$ of DSS treatment.
E-GPx mRNA, when normalized to the amount of GAPD mRNA, as early as $3 \mathrm{~d}$ after DSS treatment ( $p<0.05$; Fig. 5). However, there was no significant difference in C-GPx mRNA in the kidney or lower GI tract (data not shown) between the two groups after $7 \mathrm{~d}$ of DSS treatment. Therefore, increased plasma E-GPx is associated with a specific increase in E-GPx mRNA in the kidney.
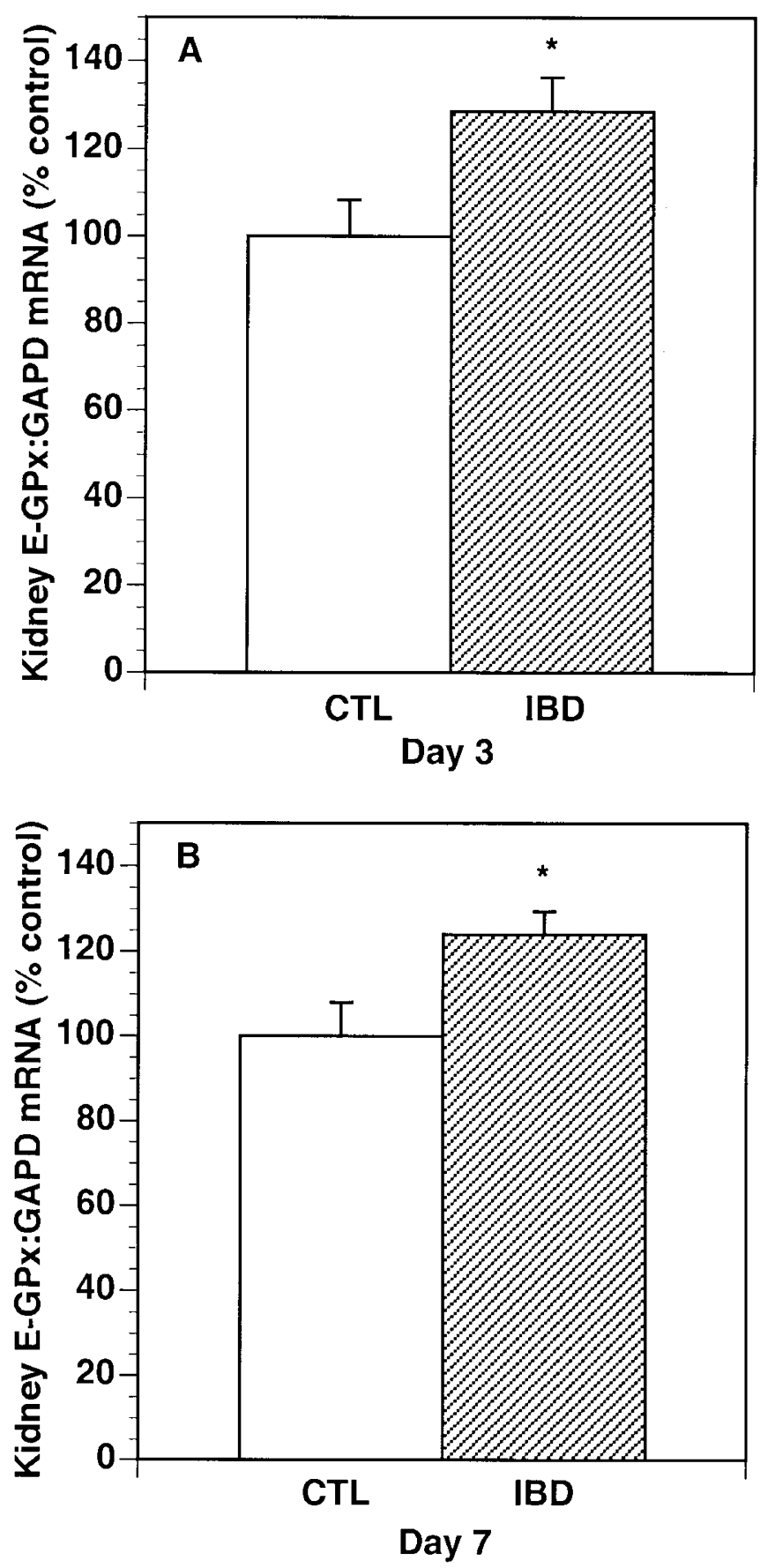

Figure 5. E-GPx mRNA in mouse IBD. Total RNA from mouse kidney was isolated and probed by Northern blot as described in "Methods." The amount of E-GPx mRNA is normalized to the amount of GAPD. Data are presented as percent of control. Kidney E-GPx mRNA from the IBD group is significantly increased by $29 \%$ after $3 \mathrm{~d}$ of DSS treatment and $24 \%$ after $7 \mathrm{~d}$ of DSS treatment $(* p<0.05$, unpaired $t$ test). 


\section{DISCUSSION}

Orally administered DSS produces reproducible colitis in mice. The pathogenesis is unknown but mechanisms such as direct toxic effects on the mucosal epithelium, direct toxic effects on the crypt epithelium, and DSS-induced inflammation have been proposed (20). This mouse model of IBD has been valuable for the study of mechanisms that could act in the pathogenesis of human ulcerative colitis because treatment with DSS in this manner results in an acute ulceration, followed by healing and repair (20).

Previous human studies have reported that pediatric patients with IBD have an increase in GPx activity in their plasma (18, 19). In our present mouse studies, we have demonstrated that plasma GPx activity increased in a DSS mouse model of IBD, which is attributable to a concomitant increase in plasma E-GPx protein. In addition, we observed an increase in distal colon E-GPx after $7 \mathrm{~d}$ of DSS treatment. We did not, however, detect any changes in E-GPx protein or mRNA in the cecum or proximal colon. Northern analysis studies suggest that the source of increased plasma GPx activity probably arose from the kidney. There is an increase in E-GPx mRNA levels in the kidney, whereas E-GPx mRNA in the intestine does not change. Because the DSS mouse model demonstrated changes in plasma GPx activity similar to IBD in humans $(18,19)$, we believe that this is a good model for studying the role of oxidants and antioxidants in IBD.

In recent studies, our laboratory has demonstrated an increase in plasma GPx activity related to an increase in plasma E-GPx protein after hyperoxia exposure (23). Similar to the response in hyperoxia-exposed mice, our study with experimental colitis also demonstrated that the resultant increase in plasma GPx activity is related to an increase in plasma E-GPx protein. In this IBD study, the increase in plasma GPx activity and E-GPx protein is associated with an increase in E-GPx mRNA levels in the kidney. These results imply that renal production of E-GPx may be sensitive to distal insults, such as inflammation, oxidant stress, or tissue damage occurring in the GI tract, or other organs such as the lung. The kidney may respond to these distal insults by an increase in E-GPx mRNA with a resultant increase in E-GPx in the plasma. This study provides evidence that IBD may be associated with altered circulating antioxidants. The role of E-GPx in protecting the GI tract and the whole body from oxidative damage warrants further study. Further studies involving other inflammatory situations should be investigated to determine mechanisms responsible for the up-regulation of plasma E-GPx.

Recently Esworthy et al. (24) showed that the combined inactivation of C-GPx and GI-GPx results in IBD in mice. Such genetic experiments may be necessary to further investigate the role of E-GPx in disorders involving inflammation such as in IBD. Inactivation of E-GPx, alone and in combination with other GPx, should delineate the contributions of these molecules in IBD.

\section{REFERENCES}

1. Parks DA, Bulkley GB, Granger DN 1983 Role of oxygen-derived free radicals in digestive tract diseases. Surgery 94:415-422

2. Tsuchiya M 1988 Free radicals in digestive diseases. In: Proceedings of the 1st International Symposium on Free Radicals in Digestive Diseases. Excerpta Medica, New York, pp 244

3. Baker SS, Campbell CL 1989 Enterocyte injury by $\mathrm{O}_{2}$-dependent processes. Gastroenterology 96:A23(abstr)

4. Keshavarzian A, Sedghi S, Kanofsky J, List T, Robinson C, Ibrahim C, Winship D 1992 Excessive production of reactive oxygen metabolites by inflamed colon: analysis by chemiluminescence probe. Gastroenterology 103:177-185

5. Simmonds NJ, Allen RE, Stevens TR, Van Someren RN, Blake DR, Rampton DS 1992 Chemiluminescence assay of mucosal reactive oxygen metabolites in inflammatory bowel disease. Gastroenterology 103:186-196

6. Esworthy RS, Chu FF, Geiger P, Girotti AW, Doroshow JH 1993 Reactivity of plasma glutathione peroxidase with hydroperoxide substrates and glutathione. Arch Biochem Biophys 307:29-34

7. Yamamoto Y, Takahashi K 1993 Glutathione peroxidase isolated from plasma reduces phospholipid hydroperoxides. Arch Biochem Biophys 305:541-545

8. Yamamoto Y, Nagata Y, Niki E, Watanabe K, Yoshimura S 1993 Plasma glutathione peroxidase reduces phosphatidylcholine hydroperoxide. Biochem Biophys Res Commun 193:133-138

9. Avissar N, Ornt DB, Yagil Y, Horowitz S, Watkins RH, Kerl EA, Takahashi K, Palmer IS, Cohen HJ 1994 Human kidney proximal tubules are the main source of plasma glutathione peroxidase. Am J Physiol 266:C367-C375

10. Avissar N, Finkelstein JN, Horowitz S, Willey JC, Coy E, Frampton MW, Watkins RH, Khullar P, Xu YL, Cohen HJ 1996 Extracellular glutathione peroxidase in human lung epithelial lining fluid and in lung cells. Am J Physiol 270:L173-L182

11. Avissar N, Eisenmann C, Breen JG, Horowitz S, Miller RK, Cohen HJ 1994 Human placenta makes extracellular glutathione peroxidase and secretes it into maternal circulation. Am J Physiol 267:E68-E76

12. Kingsley PD, Whitin JC, Cohen HJ, Palis J 1998 Developmental expression of extracellular glutathione peroxidase suggests antioxidant roles in deciduum, visceral yolk sac, and skin. Mol Reprod Dev 49:343-355

13. Avissar N, Slemmon JR, Palmer IS, Cohen HJ 1991 Partial sequence of human plasma glutathione peroxidase and immunologic identification of milk glutathione peroxidase as the plasma enzyme. J Nutr 121:1243-1249

14. Whitin JC, Tham DM, Bhamre S, Ornt DB, Scandling JD, Tune BM, Salvatierra O, Avissar N, Cohen HJ 1998 Plasma glutathione peroxidase and its relationship to renal proximal tubule function. Mol Gen Metab 65:238-245

15. Esworthy RS, Mann JR, Sam M, Chu FF 2000 Low glutathione peroxidase activity in Gpx1 knockout mice protects jejunum crypts from gamma-irradiation damage. Am J Physiol 279:G426-G436

16. Tham DM, Whitin JC, Kim KK, Zhu SX, Cohen HJ 1998 Expression of extracellular glutathione peroxidase in human and mouse gastrointestinal tract. Am J Physiol 275:G1463-G1471

17. Lih-Brody L, Powell SR, Collier KP, Reddy GM, Cerchia R, Kahn E, Weissman GS, Katz S, Floyd RA, McKinley MJ 1996 Increased oxidative stress and decreased antioxidant defenses in mucosa of inflammatory bowel disease. Dig Dis Sci 41:20782086

18. Hoffenberg EJ, Deutsch J, Smith S, Sokol RJ 1997 Circulating antioxidant concentrations in children with inflammatory bowel disease. Am J Clin Nutr 65:1482-1488

19. Thomas AG, Miller V, Shenkin A, Fell GS, Taylor F 1994 Selenium and glutathione peroxidase status in pediatric health and gastrointestinal disease. J Pediatr Gastroenterol Nutr 19:213-219

20. Okayasu I, Hatakeyama S, Yamada M, Ohkusa T, Inagaki Y, Nakaya R 1990 A novel method in the induction of reliable experimental acute and chronic ulcerative colitis in mice. Gastroenterology 98:694-702

21. Avissar N, Kerl EA, Baker SS, Cohen HJ 1994 Extracellular glutathione peroxidase mRNA and protein in human cell lines. Arch Biochem Biophys 309:239-246

22. Beutler E 1984 Red cell metabolism: a manual of biochemical methods. Grune \& Stratton, Orlando, FL, p 188

23. Kim KK, Whitin JC, Sukhova NM, Cohen HJ 1999 Increase in extracellular glutathione peroxidase in plasma and lungs of mice exposed to hyperoxia. Pediatr Res 46:715-721

24. Esworthy RS, Aranda R, Martin MG, Doroshow JH, Binder SW, Chu FF 2001 Mice with combined disruption of Gpxl and Gpx2 genes have colitis. Am J Physiol 281:G848-G855 